\title{
Remote continuity of learning and the COVID-19 pandemic: Educators' self-perceptions of preparedness
}

\author{
Marjorie Ceballos, Thomas Vitale and William R. Gordon \\ University of Central Florida, United States \\ Correspondence should be addressed to Marjorie Ceballos iD marjorie.ceballos@ucf.edu \\ Received 8 February 2021; Revised 19 March 2021; Accepted 28 July 2021
}

\begin{abstract}
In February 2020, the COVID-19 pandemic upended education systems as schools suspended in-person instruction and transitioned to remote learning to mitigate the spread of the disease within their communities. As school systems implemented remote learning, we sought to examine differences in teacher and educational leader self-perceptions of preparedness for remote continuity of learning and communicating with stakeholders, factors contributing to preparedness, and recommended needs in future educational leadership preparation. We used a survey design to complete this research by distributing the Self-perceptions of Preparedness for Remote Continuity of Learning Instrument (SPRCLI) (C) to a convenience sample of teachers and educational leaders enrolled in a graduate-level educational leadership program. Eighty teachers and 15 educational leaders completed the SPRCLI @ survey. Analysis indicated differences in self-perceptions of preparedness to communicate with stakeholders with educational leaders demonstrating higher perceptions of communication preparedness. Contributing factors for preparedness for remote continuity of learning included colleagues, professional development, prior technology experience, and experiences with online learning. Participants recommended future educational leadership preparation include professional development and coursework on digital applications, best practices for remote learning, and development of school plans for remote continuity of learning. This study contributes to an understanding of teacher and educational leader preparedness for remote learning at the start of the COVID-19 crisis.
\end{abstract}

Keywords: Remote continuity of learning, school administration, school preparedness, educational leadership preparation

\section{Introduction}

The devastating impact of COVID-19 and its effect on various sectors of industry created unprecedented challenges and uncertain times (Deloitte, n. d.) worldwide. The education sector was not immune to the impact of COVID-19 as schools, colleges, and universities closed (United Nations Educational, Scientific and Cultural Organization, n. d.). According to UNESCO (n. d.), COVID-19 resulted in disruptions in learning to more than 1.5 billion students and youths worldwide. As of August 2020, more than 100 countries had not opened schools and had not established a future opening date (UNESCO, n. d.).

The resulting effects of the COVID-19 pandemic on schools shed light on the need to have a renewed focus on and restructuring of educational leaders' preparation to respond to crises that lead to school closures (Harris \& Jones, 2020), while attending to students' academic needs. At the outset of the COVID-19 pandemic in March 2020 when stay-at-home orders were issued, there was a lack of research on teachers' and educational leaders' self-perceptions of preparedness for remote learning. The purpose of this study was two-fold. First, we aimed to examine teachers' and practicing educational leaders' self-perceptions of preparedness for remote continuity of learning related to instruction and communicating with stakeholders. A second purpose was to identify potential future needs in educational leadership preparation. 


\subsection{Literature Review}

Preparedness and the ability to respond to the pandemic created disparities throughout the education sector as educational systems strove to continue to provide services in a remote learning environment. Fragile education systems (UNESCO, n. d.) and locations where remote continuity of learning from home were minimal or non-existent were the most impacted. Schools in the United States faced issues similar to those experienced worldwide. While school closures were not the norm in the U.S., early discourse on how to mitigate the impact of the crisis was non-productive (Harris \& Jones, 2020). As more was learned about COVID-19, more guidelines were provided for educational institutions to follow, impacting the way educational leaders managed their schools. In educational systems in the United States, guidance on safety and disease control was provided by the Center for Disease Control (CDC, 2020). School-based contingency planning, (i.e., crisis management and emergency management), in a pandemic became essential to developing responses due to the uncertainty of COVID-19 in schools and school districts throughout the United States (Anderson, 2020). During the H1N1 epidemic in the United States, the U.S. Department of Education (USDOE, 2009) released guidance to schools regarding development of plans for continuity of learning due to student absences or school closures. The USDOE guidance included recommendations on availability of curricular materials for students and resources (i.e., hard copies and/or digital materials available to students at home) and strategies to address needs across a variety of schools and student subgroups. The overarching purpose was to provide a document that provided considerations for planning to ensure continuity of learning due to an epidemic. Given the demands placed on educational leaders at the start of the pandemic, the literature reviewed here provides context on school closures due to outbreaks of disease, guidance for remote continuity of learning, crisis management, and leadership orientations during crises.

\subsubsection{School closures and remote continuity of learning}

School closures historically have been used to limit the spread of disease within communities. For example, in 1883 England sanitary authorities debated the effectiveness of school closures in controlling outbreaks of measles and scarlatina (British Medical Journal, 1883). Similarly, to limit the spread of an outbreak of polio that presaged the polio pandemic of 1949-1952, the superintendent of Chicago's public schools closed schools for three weeks in 1937 (Tucker, 2020). As we know, many schools closed worldwide in early 2020 in response to the COVID-19 pandemic, transitioning to remote continuity of learning. In China where stay-at-home orders were issued early in the pandemic, Zhang et al. (2020) examined the preliminary policy considerations of the Chinese Ministry of Education's 'suspending classes without stopping learning' (p. 2). Although the Chinese Ministry of Education had integrated national resources, provided professional learning for teachers on online teaching, and had considerations for local contexts, Zhang et al. (2020) discovered various educational policy issues that needed to be addressed. Policy issued included the technology infrastructure available, online teaching resources and teachers' use of those resources, distractions in the home environment for both teachers and students, and teaching modes and online teaching pedagogy (Zhang et al., 2020).

In the United States, where public education is the prerogative of individual states, state departments of education provided guidance for remote continuity of learning that included instructional resources, parent communication strategies for schools, addressing the needs of student subgroups (e.g., English learners, students with disabilities, and under-resourced students), and teacher professional learning for online instruction. For instance, Michigan offered professional learning for blended instruction that included topics such as assessment in blended learning, blended classroom design, and the use of applications like Kahoot (Michigan Department of Education, n. d.). Resources to address the needs of subgroups included instructional resources as well as parent communication strategies and parent resources for use during remote continuity of learning (New Jersey Department of Education, n. d.). In Florida, where this study was completed, the state department of education provided online professional learning for teachers, 
instructional resources, resources for teachers and families, and resources to address the needs of English learners (Florida Department of Education, n. d.). Additionally, individual school districts in the state also provided remote learning guidance documents for their schools to use. MiamiDade County Public Schools' (n. d.) remote continuity plan included information on content delivery, mobile devices, internet access, and resource documents for parents and students. The provision of resources for schools and school districts during remote continuity of learning was a critical response to the pandemic. Equally important to the task was leadership employed by school and school district leaders.

\subsubsection{Crisis management and leadership}

Crisis management informs the work of school leaders during emergency periods. Several researchers have examined the critical nature of crisis management plans in response to natural disasters and other school crises (Barker \& Yoder, 2012; Baytiyeh, 2019; Gainey, 2009; Smith \& Riley, 2012). One of the major challenges in devising crisis management plans is that crises, by their very nature, tend to be contextual and, as such, the response should be tailored to meet the specific crisis (Barker \& Yoder, 2012). Gainey (2009) argued that crisis management planning should be an essential aspect of school district leadership during the strategic planning process, including consistent updates to the plan, analysis of strengths and weaknesses, and analysis of leadership during a crisis.

The effects of crisis management planning can be seen in the response to remote continuity of learning exhibited by higher education (HE) institutions. While primary and secondary school systems struggled to meet the challenges of remote continuity of learning in the United States, colleges and universities were better positioned to meet those challenges. HE institutions with well-prepared and well-established crisis management processes that were reviewed and updated on a consistent basis were likely to be positioned to respond and mitigate the outcomes of an event (Zdziarski II, 2016, p. 27). Holzweiss and Walker (2018) stated that HE administrators incorporated crisis management into their leadership development due to natural disasters and active shooter incidents that occurred on campuses (p. 124). Crisis management planning, therefore, was critical to HE institutions' ability to manage the effects of the COVID-19 pandemic in the short term. However, pandemics that create short and long-term school closures and or impacted the health and safety of students and staff were not typically included in planning (Anderson, 2020).

In addition to having comprehensive crisis management plans, leadership attributes also play a role in responses to crises, allowing educational leaders to pivot to address the elements of the crisis. Smith and Riley (2012) differentiated leadership during routine times and times of crisis when school leaders are focused on dealing with 'events, emotions, and consequences' (p. 57) of a crisis. Crisis leadership requires nine key leadership competencies, including decisive decisionmaking, communication skills, procedural intelligence, synthesizing skills, optimism and tenacity, flexibility, intuition, empathy and respect, and creativity and lateral thinking (Smith \& Riley, 2012, Figure 3, p. 68). Furthermore, to prepare for potential crises, school leaders need to engage in crisis audits that focus on uncovering what could cause major problems for a school, the probability of each type of problem/crisis, effects of the crisis on the school, and factors that could prevent the crisis (Smith \& Riley, 2012). The findings from Hauseman et al.'s (2020) analysis of Canadian school leaders' work during COVID-19 underscored the key competencies of crisis leadership in practice. Researchers found that during COVID-19, school leaders had to expend more effort when it came to providing additional support for students and teachers, learn and adopt new policies and job requirements within a short time period, model collaboration, and provide continuous, 'transparent' communication to the 'school community' (Hauseman et al., 2020, p. 72).

The communication acumen of school leaders was an important component of crisis leadership at the start of the pandemic when communicating with faculty and school community during COVID-19 (Netolicky, 2020). Brelsford et al. (2020) found that teachers perceived school leader communication during COVID-19 school closures was best when it was 'proactive' rather than 'reactive,' 'transparent,' 'accurate,' and continuous (p. 13). Additionally, communication and 
collaboration between school leaders and teachers were critical for reflecting, problem-solving, sharing of instructional expertise, and receiving guidance for communicating with parents (Brelsford et al., 2020; Hauseman et al., 2020). In addition to communication for instructional support and providing information to the community, school leaders also had to provide support for the health and well-being of faculty and students (Brelsford et al., 2020; Netolicky, 2020).

The constructs found in the literature including, school closures due to outbreaks of disease, guidance for remote continuity of learning, crisis management, and leadership orientations during crises served to inform this research on educators' self-perceptions of preparedness for continuity of learning. To complete the study, we used a convenience sample of teachers and educational leaders enrolled in a graduate-level educational leadership preparation program (i.e., master's, specialist, or doctoral-level students). This study focused on the following three research questions: (1) what are the differences, if any, between the self-perceptions of preparedness for remote continuity of learning of teachers and educational leaders? (2) what are the factors that contributed to teacher and educational leader self-perceptions of preparedness for remote continuity of learning, and (3) what are the recommendations for future educational leadership preparation for remote continuity of learning?

\section{Methodology}

The purpose of this research study was to collect self-perceptions of preparedness for remote continuity of learning following the stay-at-home orders that were issued in spring 2020. To complete this research study, we designed the Self-perceptions of Preparedness for Remote Continuity of Learning Instrument (SPRCLI) ( ). The SPRCLI (c) aimed to collect information from participants on their self-perceptions of preparedness for remote continuity of learning for instruction, communication, factors that contributed to participants' preparation, and recommendations for future educational leader preparation.

\subsection{Research Design and Sample}

To complete the study, a survey design was utilized to collect descriptive data (Creswell \& Creswell, 2018) on participants' self-perceptions of preparedness for remote continuity of learning for instruction, communication, factors contributing to participants preparation, and participants' recommendations for future educational leader preparation. Additionally, we used the survey design because it would allow us to determine if any differences existed between participant groups or by years in education and position when examining self-perceptions of preparedness for remote continuity of learning for instruction and communication. By employing a survey design, we were able to gather descriptive information on participants' self-perceptions of preparedness and to examine the data for differences among participants (Creswell \& Creswell, 2018).

Data for the study were collected through the SPRCLI @ . We distributed the SPRCLI @ through Qualtrics to a convenience sample of teachers and educational leaders enrolled in a graduate-level educational leadership preparation program (i.e., master's, specialist, or doctoral-level students) at a large Florida public university in the Spring 2020 semester. The educational leadership program included both aspiring and practicing educational leaders, enrolled in a master's, specialist, or doctoral program. Aspiring educational leaders included teachers, instructional coaches, and/or academic deans. Practicing educational leaders included principals, assistant principals, and school district-level administrators. In the following sections we refer to aspiring educational leaders as teachers and to practicing educational leaders as educational leaders. We used this convenience sample of educators because it allowed us to gather information on self-perceptions of preparedness from both teachers and educational leaders operating at various levels of the organization when stay-at-home orders were issued in Florida. Moreover, because participants in this convenience sample were enrolled in an educational leadership program at the time when stay-at-home orders were issued, the convenience sample would provide teachers' and educational leaders' recommendations for future educational leader preparation based on their inthe-moment experiences with remote continuity of learning due to COVID-19. 


\subsection{Self-perceptions of Preparedness for Remote Continuity of Learning Instrument}

The SPRCLI ( ) consisted of 20 items and 42 sub-items in five sections: (1) demographic information of participants, (2) perceptions of preparedness for remote continuity of learning of teachers (3) perceptions of preparedness for remote continuity of learning of educational leaders, (4) factors contributing to teacher and educational leader preparedness and (5) open-ended questions related to additional factors contributing to preparedness and future recommendations for educational leadership preparation. To create the survey items, we used the guidance issued by the U.S. Department of Education (2009) for remote continuity of learning and research on distance education (Hattie, 2009). It was necessary for us to create the survey instrument because at the time of the study, there was a dearth of instruments that measured preparedness for remote continuity of learning as a result of a pandemic. The survey was designed using the tailored design method as explained by Dillman et al. (2009).

Section one of the survey collected demographic information from participants, including degree program, professional role, and professional experiences. Sections two and three of the survey included four items comprised of 42 Likert-scaled sub-items addressing components related preparedness for remote continuity of learning and preparedness to communicate with stakeholders. Each Likert-scaled item ranged from 1 to 4 where $1=$ "not prepared," 2 = "somewhat prepared," $3=$ "prepared," and $4=$ "very prepared." The Likert-scaled sub-items in section two of the survey were designed for teacher participants, while the sub-items in section three were designed for educational leader participants. The sub-items in sections two and three mirrored each other so that comparisons could be made between teacher and educational leader participants. The components included in the sub-items are outlined in Table 1.

Table 1

Preparedness for Remote Continuity of Learning and Communication Components

\begin{tabular}{|c|c|c|c|c|}
\hline & $\begin{array}{l}\text { Participant } \\
\text { Group }\end{array}$ & $\begin{array}{l}\text { Survey } \\
\text { Item }\end{array}$ & $\begin{array}{l}\text { Number of } \\
\text { Sub-items }\end{array}$ & Components \\
\hline \multirow{6}{*}{$\begin{array}{l}\text { Preparedness } \\
\text { for Remote } \\
\text { Continuity of } \\
\text { Learning }\end{array}$} & Teacher & 14 & 13 & \multirow{6}{*}{$\begin{array}{l}\text { Using technology for instruction } \\
\text { Providing resources for learners, online } \\
\text { and hard copy } \\
\text { Providing learners opportunities to } \\
\text { collaborate with peers, in real-time and } \\
\text { not in real-time } \\
\text { Providing social emotional support } \\
\text { Addressing the needs of English learners, } \\
\text { learners with disabilities, and under- } \\
\text { resourced learners }\end{array}$} \\
\hline & & & & \\
\hline & Educational & 15 & 13 & \\
\hline & Leader & & & \\
\hline & & & & \\
\hline & & & & \\
\hline \multirow{6}{*}{$\begin{array}{l}\text { Preparedness to } \\
\text { Communicate } \\
\text { with } \\
\text { Stakeholders }\end{array}$} & Teacher & 16 & 7 & \multirow{3}{*}{$\begin{array}{l}\text { Communicating and collaborating with } \\
\text { peers in similar professional roles for } \\
\text { instruction }\end{array}$} \\
\hline & Educational & 17 & 9 & \\
\hline & Leader & & & \\
\hline & & & & Communicating with supervisors \\
\hline & & & & $\begin{array}{l}\text { Communicating with parents/guardians } \\
\text { and learners }\end{array}$ \\
\hline & & & & $\begin{array}{l}\text { Communicating expectations for remote } \\
\text { continuity of learning to } \\
\text { parents/guardians and learners }\end{array}$ \\
\hline
\end{tabular}

Section four of the survey asked participants to select and rank all the factors that contributed to their preparedness factors contributing to preparedness for remote continuity. Section five of the 
survey consisted of two open-ended items asking participants to identify additional factors contributing to preparedness and to make recommendations for future educational leader preparation. Prior to disseminating the survey, items were analyzed for validity, clarity, and relevance by content experts. Reliability coefficients were calculated, evaluated, and found to be .8 or greater for all Likert-scaled items (item 14, $\alpha=.907$; item 15, $\alpha=.898$; item 16, $\alpha=.878$; item 17, $\alpha=.827$ ), indicating acceptable reliability (Mueller \& Knapp, 2019).

\subsection{Data Analysis}

Analysis of the Likert-scaled items and ranking of factors contributing to preparedness consisted of descriptive analysis, independent samples t-tests, and one-way analysis of variances (ANOVAs). To analyse the two open-ended items asking participants to identify additional factors that contributed to their preparedness for remote continuity of learning and make recommendations to prepare future educational leaders for remote continuity of learning, we utilized In Vivo coding to 'prioritize and honor the participant's voice' (Saldaña, 2016, p. 295) and used the constant comparative method to reduce and integrate categories (Glaser \& Strauss, 2008).

\section{Findings}

In this section, we present the findings from the Likert-scaled survey items, factors contributing to preparedness, and open-ended items. For Likert-scaled survey items, we present mean item scores and mean sum scores for preparedness for remote learning and communicating during remote continuity of learning, comparisons of teacher and educational leader participant mean sum scores, and comparisons of mean sum scores by professional experience. For factors contributing to preparedness, we present frequencies, percentages, and mean scores. The analysis of openended items includes identified categories for additional factors contributing to preparedness and recommendations for future school leadership preparation.

\subsection{Quantitative Findings: Self-perceptions of preparedness}

Eighty teacher participants and 15 educational leadership participants responded to the survey for a total of 95 participants. First, we analyzed self-perceptions of preparedness by calculating mean scores for sections two and three sub-items. Results indicated that both teachers and educational leaders perceived a higher level of preparedness for using technology for remote learning. Likewise, both teachers and educational leaders perceived a lower level of preparedness for providing accommodations for under-resourced students and those without internet access. Table 2 presents sub-item question stems, mean scores, and standard deviations for preparedness for remote continuity of learning.

Mean scores were also calculated for individual sub-items related to preparedness to communicate. Results indicated both teachers and educational leaders perceived a higher level of preparedness to communicate for various purposes with a variety of school stakeholder groups. Table 3 presents question stems, sub-items, mean scores, and standard deviations for preparedness to communicate with stakeholders. 
Table 2

Teacher and Educational Leader Preparedness for Remote Learning

\begin{tabular}{|c|c|c|c|}
\hline $\begin{array}{l}\text { Participant } \\
\text { Group }\end{array}$ & Sub-item & M & $S D$ \\
\hline \multirow[t]{14}{*}{ Teacher } & Survey Item Stem: My level of preparedness to... & & \\
\hline & Use technology for remote instruction & 3.24 & 0.92 \\
\hline & Provide learners access to instructional materials online & 2.97 & 0.98 \\
\hline & Help learners to learn independently & 2.81 & 1.10 \\
\hline & $\begin{array}{l}\text { Provide support to learners for social emotional learning and } \\
\text { support }\end{array}$ & 2.57 & 1.05 \\
\hline & $\begin{array}{l}\text { Provide instructional opportunities for learners to collaborate } \\
\text { remotely with peers for completion of learning tasks, not in } \\
\text { real-time }\end{array}$ & 2.41 & 1.23 \\
\hline & $\begin{array}{l}\text { Provide instructional opportunities for learners to collaborate } \\
\text { remotely with peers for completion of learning tasks, in real- } \\
\text { time }\end{array}$ & 2.37 & 1.18 \\
\hline & Provide real-time class sessions for learners & 2.32 & 1.32 \\
\hline & Provide accommodations for English learners & 2.20 & 1.28 \\
\hline & Provide pre-recorded sessions for learners & 2.11 & 1.35 \\
\hline & Provide accommodations for learners with disabilities & 2.11 & 1.14 \\
\hline & $\begin{array}{l}\text { Provide learners access to paper copies of instructional } \\
\text { materials }\end{array}$ & 2.03 & 1.33 \\
\hline & $\begin{array}{l}\text { Provide support for under-resourced populations who may be } \\
\text { unable to engage in learning remotely }\end{array}$ & 1.90 & 1.07 \\
\hline & $\begin{array}{l}\text { Provide accommodations for learners who do not have } \\
\text { internet access }\end{array}$ & 1.76 & 1.11 \\
\hline \multirow[t]{14}{*}{$\begin{array}{l}\text { Educational } \\
\text { Leaders }\end{array}$} & $\begin{array}{l}\text { Survey Item Stem: My level of preparedness to support others } \\
\text { in... }\end{array}$ & & \\
\hline & Using technology for remote instruction & 3.00 & 0.76 \\
\hline & Providing learners access to instructional materials online & 3.00 & 0.85 \\
\hline & Providing real-time class sessions for learners & 2.67 & 0.72 \\
\hline & $\begin{array}{l}\text { Providing instructional opportunities for learners to } \\
\text { collaborate remotely with peers for completion of learning } \\
\text { tasks, not in real-time }\end{array}$ & 2.67 & 0.90 \\
\hline & $\begin{array}{l}\text { Providing instructional opportunities for learners to } \\
\text { collaborate remotely with peers for completion of learning } \\
\text { tasks, in real-time }\end{array}$ & 2.60 & 0.91 \\
\hline & Helping learners to learn independently & 2.53 & 0.83 \\
\hline & $\begin{array}{l}\text { Providing learners access to paper copies of instructional } \\
\text { materials }\end{array}$ & 2.47 & 0.99 \\
\hline & Providing pre-recorded sessions for learners & 2.47 & 0.92 \\
\hline & $\begin{array}{l}\text { Providing support to learners for social emotional learning } \\
\text { and support }\end{array}$ & 2.40 & 1.18 \\
\hline & Providing accommodations for English learners & 2.33 & 1.29 \\
\hline & Provide accommodations for learners with disabilities & 1.93 & 1.22 \\
\hline & $\begin{array}{l}\text { Providing accommodations for learners who do not have } \\
\text { internet access }\end{array}$ & 1.80 & 1.08 \\
\hline & $\begin{array}{l}\text { Provide support for under-resourced populations who may be } \\
\text { unable to engage in learning remotely }\end{array}$ & 1.67 & 1.18 \\
\hline
\end{tabular}

Note. $1=$ not prepared, $2=$ somewhat prepared, $3=$ prepared, and $4=$ very prepared. 
Table 3

Teacher and Educational Leader Preparedness to Communicate

\begin{tabular}{|c|c|c|c|}
\hline $\begin{array}{l}\text { Participant } \\
\text { Group }\end{array}$ & Item & M & $S D$ \\
\hline \multirow[t]{8}{*}{ Teacher } & $\begin{array}{l}\text { Item Question Stem: My level of preparedness to } \\
\text { communicate... }\end{array}$ & & \\
\hline & $\begin{array}{l}\text { With others who have similar responsibilities to collaborate on } \\
\text { and/or share strategies, resources, etc. for remote continuity of } \\
\text { learning }\end{array}$ & 3.22 & 0.87 \\
\hline & With my administrator regarding learner progress & 3.19 & 1.03 \\
\hline & $\begin{array}{l}\text { With my others who have similar responsibilities to plan for } \\
\text { remote continuity of learning }\end{array}$ & 3.18 & 0.94 \\
\hline & $\begin{array}{l}\text { With learners via telephone, email, text messaging, or web } \\
\text { conferencing regarding learner progress }\end{array}$ & 3.09 & 0.98 \\
\hline & With parents/guardians regarding learner progress & 2.93 & 1.26 \\
\hline & $\begin{array}{l}\text { Instructional expectations for remote continuity of learning to } \\
\text { learners }\end{array}$ & 2.89 & 1.17 \\
\hline & $\begin{array}{l}\text { Instructional expectations for remote continuity of learning to } \\
\text { parents/guardians }\end{array}$ & 2.62 & 1.34 \\
\hline \multirow[t]{10}{*}{$\begin{array}{l}\text { Educational } \\
\text { Leaders }\end{array}$} & $\begin{array}{l}\text { Item Question Stem: My level of preparedness to } \\
\text { communicate... }\end{array}$ & & \\
\hline & With my supervisor regarding remote continuity of learning & 3.67 & 0.49 \\
\hline & $\begin{array}{l}\text { With my leadership team to collaborate on and/or share } \\
\text { strategies, resources, etc. related to remote continuity of } \\
\text { learning }\end{array}$ & 3.53 & 0.52 \\
\hline & $\begin{array}{l}\text { With my school leadership team for remote continuity of } \\
\text { learning }\end{array}$ & 3.47 & 0.64 \\
\hline & $\begin{array}{l}\text { To instructional personnel expectations for learners' remote } \\
\text { continuity of learning }\end{array}$ & 3.33 & 0.62 \\
\hline & $\begin{array}{l}\text { With instructional personnel via telephone, email, text } \\
\text { messaging, or web conferencing regarding learner progress }\end{array}$ & 3.33 & 0.82 \\
\hline & With parents/guardians regarding learner progress & 3.07 & 1.10 \\
\hline & $\begin{array}{l}\text { With peers at other schools to collaborate on and/or share } \\
\text { strategies, resources, etc. for remote continuity of learning }\end{array}$ & 2.80 & 1.01 \\
\hline & $\begin{array}{l}\text { To parents/guardians instructional expectations for remote } \\
\text { continuity of learning }\end{array}$ & 2.73 & 1.10 \\
\hline & $\begin{array}{l}\text { With the school district-level regarding remote continuity of } \\
\text { learning }\end{array}$ & 2.33 & 1.45 \\
\hline
\end{tabular}

Note. $1=$ not prepared, $2=$ somewhat prepared, $3=$ prepared, and $4=$ very prepared.

\subsubsection{Overall self-perceptions of preparedness}

To determine the overall self-perceptions of preparedness of teachers and educational leaders for remote continuity of learning and communicating with stakeholders, a total mean sum score was calculated for the 20 sub-items in sections two (item $14 \Sigma=52$; item $15 \Sigma=28$ ) and the 22 sub-items in section three (item $16 \Sigma=52$; item $17 \Sigma=36$ ). Overall, educational leaders demonstrated higher mean sum scores than teachers in preparedness for remote continuity of learning and preparedness to communicate with stakeholder groups.

An independent samples $t$-test used to compare the mean sum scores of teachers' and educational leaders' self-perceptions of preparedness for remote continuity of learning indicated 
no significant difference, $t(23)=-0.291, p=.77$. The independent samples $t$-test used to compare the mean sum scores of teacher and educational leader perceptions of preparedness to communicating with various stakeholder groups during remote continuity of learning demonstrated a significant difference, $t(21)=-4.678, p=.00$. The finding indicated that educational leaders perceived themselves to be more prepared to communicate with various stakeholder groups than teachers did. Table 4 presents the mean sum scores, standard deviations, and results of the independent samples $t$-test for each participant group.

Table 4

Mean Sum Scores by Participant Group and Results of t-tests

\begin{tabular}{|c|c|c|c|c|c|c|c|c|c|c|c|}
\hline \multicolumn{12}{|c|}{ Participant Group } \\
\hline & \multicolumn{3}{|c|}{ Teachers } & \multicolumn{3}{|c|}{$\begin{array}{l}\text { Educational } \\
\text { Leaders }\end{array}$} & \multirow[t]{2}{*}{$\begin{array}{c}\text { Mean } \\
\text { Difference }\end{array}$} & \multirow[t]{2}{*}{$\begin{array}{l}\text { Std. Error } \\
\text { Difference }\end{array}$} & \multirow[t]{2}{*}{$t$} & \multirow[t]{2}{*}{$d f$} & \multirow[t]{2}{*}{$p$} \\
\hline & $M$ & $S D$ & $n$ & $M$ & $S D$ & $n$ & & & & & \\
\hline $\begin{array}{l}\text { Preparedness } \\
\text { for Remote } \\
\text { Continuity of } \\
\text { Learning }\end{array}$ & 30.83 & 10.40 & 80 & 31.53 & 8.31 & 15 & -0.71 & 2.44 & -0.291 & 23.08 & .77 \\
\hline $\begin{array}{l}\text { Preparedness } \\
\text { to } \\
\text { Communicate } \\
\text { with Various } \\
\text { Stakeholder } \\
\text { Groups }\end{array}$ & 21.11 & 6.04 & 80 & 28.27 & 5.32 & 15 & -7.61 & 1.53 & $-4.678^{*}$ & 21.36 & .00 \\
\hline
\end{tabular}

Note. $N=95$. Total sum scores for survey items $14(\Sigma=52), 15(\Sigma=28), 16(\Sigma=52)$, and $17(\Sigma=36)$. Items 14 and 16 collected data on preparedness for remote continuity of learning and items 15 and 17 on communication for participant groups. Equal variances not assumed.

\subsubsection{Professional experience variables and preparedness for remote continuity of learning}

For this analysis, the participant groups of teachers and educational leaders were analyzed as an aggregated group. Through this analysis, we sought to understand if professional longevity contributed to differences in perceptions of preparedness for remote continuity of learning. To examine differences in participants' self-perceptions of preparedness for remote continuity of learning based on professional experience, one-way ANOVAs were conducted on the categorical professional experience independent variables of (a) years in education and (b) years in current position.

The Levine test of homogeneity of variance indicated that the assumptions for this statistic were not violated when analyzing years in education or years in current position. For the years in education variable, participants were divided into six groups (group 1: $<5$ years $[n=29,25.0 \%]$; group 2: 5-10 years [ $n=40,34.0 \%]$; group 3: $11-15$ years $[n=22,19 \%]$; group $4: 16-20$ years $[n=15,13 \%]$; group 5: $21-25$ years $[n=10,9.0 \%]$; group $6: 26-30$ years $[n=1,1 \%])$. Results of the one-way ANOVA indicated no statistically significant differences at the $p<.05$ level for the six groups, $F(4,75)=.14$, $p=.97$. For the years in current position variable, participants were divided into five groups (group $1:<1$ year $[n=28,24.0 \%]$; group 2: $1-3$ years $[n=33,29.0 \%]$; group $3: 4-6$ years $[n=32,28 \%]$; group 4: 7-9 years $[n=10,9.0 \%]$; group $5:>9$ years $[n=12,10.0 \%])$. There were no statistically significant differences for the five groups, $F(4,75)=.645, p=.63$.

\subsubsection{Factors contributing to remote continuity of learning preparedness}

As in the professional experience analysis, teacher and educational leader participants were aggregated into one group. To determine the resources participants valued most in contributing to their preparedness, participants were asked to select which factors helped them to prepare for remote continuity of instruction. Ninety participants responded to this item, selecting colleagues (18.3\%), professional development $(14.2 \%)$, and school district level resources $(12.7 \%)$ as the top 
three factors. The factors selected least often were professional organizations $(2.2 \%)$, and statelevel resources $(2.0 \%)$. Table 5 presents the contributing factors, frequencies, and percentages from most selected to least selected factors.

Table 5

Factors Contributing to Participants' Preparedness for Remote Continuity of Learning

\begin{tabular}{lcc}
\hline Factors & $f$ & $\%$ \\
\hline Colleagues & 75 & 18.3 \\
Professional development & 58 & 14.2 \\
School district-level resources & 52 & 12.7 \\
School-level resources & 40 & 9.8 \\
Instruction / curriculum coaches & 37 & 9.0 \\
Graduate coursework & 35 & 8.5 \\
Supervisors & 30 & 7.3 \\
Vendor website (i.e., Pearson, Scholastic, etc.) & 28 & 6.8 \\
Readings & 25 & 6.1 \\
Professional organization websites & 9 & 2.2 \\
(i.e., ASCD, NASPP, NCTM, NCTE, etc.) & 8 & 2.0 \\
State-level resources & & 2 \\
\hline
\end{tabular}

Note. Participants could select more than one factor for this survey item.

Participants were then asked to rank order the list of factors they perceived most prepared them for remote continuity of learning with a rank of 1 being the most important and a rank of 12 being the least important factor. Participants ranked colleagues $(M=2.46, S D=4.48)$, professional development $(M=4.03, S D=2.39)$, and instructional/curriculum coaches $(M=5.02, S D=2.91)$ as the most valued factors. State-level resources $(M=8.07, S D=2.01)$ and professional organizations $(M=8.73, S D=2.69)$ were ranked as the least valuable. Table 6 presents the results of the ranked factors from most valued to least valued in contributing to their preparedness.

Table 6

Ranked Factors Contributing to Preparedness for Remote Continuity of Learning

\begin{tabular}{lcc}
\hline Factors & $M$ & $S D$ \\
\hline Colleagues & 2.46 & 4.48 \\
Professional development & 4.03 & 2.39 \\
Instruction / curriculum coaches & 5.02 & 2.91 \\
School district-level resources & 5.20 & 2.91 \\
School-level resources & 5.80 & 2.13 \\
Graduate coursework & 6.23 & 3.28 \\
Supervisors & 6.88 & 3.56 \\
Vendor website (i.e., Pearson, Scholastic, etc.) & 7.46 & 2.97 \\
Readings & 7.64 & 2.67 \\
State-level resources & 8.07 & 2.01 \\
Professional organization websites & 8.73 & 2.69 \\
(i.e., ASCD, NASPP, NCTM, NCTE, etc.) & &
\end{tabular}

Note. Participants ranked factors from most important (1) to least important (12).

\subsection{Open-ended Items: Additional factors contributing to preparedness and recommendations for future leadership preparation}

\subsubsection{Additional factors contributing to preparedness}

Forty participants responded to the open-ended item asking them to identify additional factors that contributed to their preparedness for remote continuity of learning. Categories generated by participants included previous technology experience and experience with online education (52.5\%), selfmotivation $(7.5 \%)$, instructional coaches $(5.0 \%)$, supportive, stable home environment $(5.0 \%)$, and clarity of 
expectations from the school district/school (5.0\%). Participants also identified several other factors that were combined under the category of other factors (25.0\%). For the previous technology experience and experience with online education category, participants pointed to their own experiences as students in online education; general experience with and knowledge of technology; previous experiences teaching in virtual settings or using technology in the classroom; and professional learning completed online. For example, one participant responded:

I felt like I was easily able to move to online learning as a teacher since I use technology all year in the classroom. My students knew how my Canvas works, where I keep the resources, and how to do their assignments. When we went to online education, there was not a big learning curve for my students except now they have embedded video lessons and online chat hours to reach me. The more technological [sic] savvy you were before the shutdown [helped] greatly with the transition. Also, I did not embed any new resource or activity the students had not seen in the class. Every website I embedded has been used in my class all year, so I think this also helped my students since they were familiar with what they had to do.

Self-motivation, instructional coaches, a supportive, stable home environment, and clarity of expectations were categories found as additional factors contributing to preparedness for remote continuity of learning. Participants indicated that a need to 'get things done,' a 'belief and desire for hybrid,' and learning through trial and error were self-motivating factors. Instructional coaches collaborating with one another across schools and within schools with teachers contributed as well. Two participants highlighted the importance of a supportive, stable home environment with one participant underscoring the support of the spouse. Finally, clarity of expectations from the school district and school was mentioned twice with both participants mentioning that school districts had issued clear guidance. However, one participant wrote that while school district expectations were clear, expectations became muddled at the school level:

Miscommunication between the [school] district and schools. The [school] district would put out a clear message of not overwhelming students with too many tasks or tasks that were too complicated, but some assistant principals communicated a different message to teachers.

The other factors category was varied and included factors such as the Canvas learning management system, a background in teaching students with disabilities, communication applications like Remind, distance learning, personal research, current remote work, teamwork among teachers, social media and social media groups, access to Zoom, and an established contingency plan at the school. Referring to the strength of teachers' teamwork, one participant wrote:

I communicated with my team constantly. We learned to use Google Classroom, Meet, and WebEx along the way. The county [school district] posted lessons that helped us create weekly assignments to complement our lesson plans. It was a team effort. By the time some help was offered, (from my school and videos from the [school] district) we were experts.

\subsubsection{Recommendations for future educational leadership preparation}

Sixty-nine participants provided recommendations for future educational leadership preparation. Participant responses addressed steps educational leadership programs could take to prepare future school leaders, while also addressing school district actions to prepare future school leaders. Categories generated by participants included professional development and coursework (42.0\%), have a plan $(13.0 \%)$, communication $(7.2 \%)$, technology embedded into classrooms (5.8\%), organizational methods and resources (5.8\%), remote learning during normal learning (4.3\%), ways to engage learners remotely $(4.3 \%)$, and student expectations $(2.9 \%)$. Participants also made various additional recommendations that were combined under the category of other recommendations (14.5\%). For the professional development and coursework category, participants outlined recommendations for professional learning needs and school leadership coursework. In terms of professional learning, participants indicated a need for comprehensive instruction on digital applications and tools for remote learning and for collaboration during professional learning to share practices and 
resources. In educational leadership preparation programs, participants expressed that instruction on remote learning should include 'practices, ethics, [and] etiquette' as well as 'scenario-based discussions, simulation experiences, [and] collaboration [sic] creation of a framework to utilize in such situations.' One participant encapsulated the need for educational leadership programs and school districts to provide instruction on remote learning:

This pandemic has surely changed instruction how we know it and I believe it will never quite be the same. Educators' lenses have [to] be broadened. On the university level, coursework on distance learning should be part of a required curriculum for Educational Leadership Programs. This coursework could include specifics on how to support different stakeholders in a distance learning environment: teachers, coaches, students, parents, etc. On a school district level, professional learning, resources, and other supports must be offered to school and district level administrators.

Having a plan, communication, technology embedded into the classrooms, organizational methods and resources, remote learning during normal learning, ways to engage learners remotely, and student expectations were identified as additional recommendations. Participants expressed the need to have a plan in place at the school and school district level for remote continuity of learning. Further, they stressed the need to familiarize all stakeholders with the remote continuity of learning plan. Educational leadership programs could assist by including learning tasks where future educational leaders could practice creating a remote continuity plan. One participant wrote:

I would like to recommend using this present time of remote continuity of learning to think of ways to prepare aspiring educators and school leaders with the know how to put together a distance learning plan. This would be a valuable project to help school leaders and educators know what available resources and tips there are on "how-to-navigate" the waters of education such as now dealing with pandemics, recession, and communicating with families. Some things cannot always be planned for, and do not go according to plan. However, having a well thought out plan to work with can be helpful. Incorporating a course component on remote learning best practices, and meaningful ways of dealing with the unexpected in education to support new instructors or school leaders at various learning levels.

The same participant continued by highlighting the need to include the lived pandemic experiences of principals and other educational leaders as part of the coursework:

I also recommend incorporating more opportunities in classes for students in the program to hear from current principals and school leaders who had to navigate through this time. These opportunities will be valuable to help prepare future leaders with remote continuity of learning for students, teachers, and administrators.

Communication competence also was highlighted as an important aspect of future educational leadership preparation. Participants emphasized communication with students, teachers, and the community and a need to be 'accessible and responsive to questions.' Furthermore, participants underscored communicating curriculum goals to students and parents. Organizational methods and resources were mentioned as well, where participants spoke to planning and keeping a schedule, organizing files online, and provision and use of resources that were 'readily available.' Moreover, ways to engage learners remotely, particularly to meet the needs of students with disabilities and under-resourced students, also was identified. Participants also described using remote learning during normal times, embedding technology into classrooms, and student expectations. For remote learning during normal times, one participant advocated for incorporating aspects of remote learning during regular schooling so that 'there would be a base from which to work if we go fully remote again.' Embedding technology into classrooms included creation of digital course shells (such as Canvas) for classes and teaching students how to use technology. Incorporating technology use in education courses also was mentioned. Lastly, student expectations focused on having a clear understanding of expectations of student work and student accountability.

The final category consisted of varied recommendations made by participants. The recommendations included having software available on laptops, considering the individual needs of teachers and students, trusting teachers to do their work, and ways to offer blended instruction 
opportunities at home (i.e., student activities that could be completed without a computer). One participant wrote that disparities in equity, student grading practices should be considered because 'inequity abounds, so grades must be given with grace and compassion.'

\section{Discussion}

The purpose of this study was to collect data on teachers' and educational leaders' self-perceptions of preparedness for remote continuity of learning at the time stay-at-home orders were issued. A second purpose was to identify potential needs in future educational leadership preparation. The first research question examined differences in teacher and educational leader self-perceptions of preparedness for remote continuity of learning and preparedness to communicate with school stakeholders. In terms of preparedness for remote continuity of learning, both teachers and educational leaders indicated a higher level of preparedness to use technology for remote learning and provide learning materials online. Likewise, both participant groups indicated a lower level of preparedness to provide accommodations for under-resourced students and students without internet access. Comparison of mean sum scores for both groups demonstrated no statistically significant difference in preparedness for remote continuity of learning.

Analysis of differences in preparedness to communicate with stakeholders did demonstrate a statistically significant difference where educational leaders exhibited a higher level of preparedness. This finding is not surprising given that communicating with stakeholders is an aspect of educational leaders' roles. Descriptive analysis revealed that both participants groups indicated higher levels of preparedness to communicate with peers and with supervisors. Both participant groups indicated a lower level of preparedness to communicate instructional expectations to parents and/or guardians. The last level of analysis was to determine if differences existed among participants in the aggregate when grouped by years in education and years in current position. Findings from this analysis demonstrated no significant difference among participants when grouped by years of professional experience, indicating that the number of years in the profession did not have an effect of self-perceptions of preparedness.

Factors contributing to participants' self-perceptions of preparedness also were investigated. Findings indicated that participants utilized colleagues, professional development, and schooldistrict resources to prepare for remote continuity of learning, while valuing colleagues and professional development most among the contributing preparedness factors. Additionally, when asked to indicate additional contributing factors, participants identified previous technology experience and experience with online education as primary contributing factors. Participants referenced their own personal experiences with technology and using technology as part of their own classroom instruction. Furthermore, participants also used their own online education experiences as students to inform their remote continuity of learning. Communication was addressed, where participants underscored the need to have clarity of expectations for remote continuity of learning and alignment of those expectations between the school district and the school.

Lastly, participants made various recommendations for future educational leadership preparation with professional development and coursework and having a plan suggested most often. Professional development included instruction on digital applications and tools for remote learning and the opportunities for collaboration during professional development offered by school districts. At the university level, participants suggested incorporating required coursework on practices, ethics, and etiquette for remote learning as well as scenario-based discussions, simulations and classroom collaboration to create remote learning frameworks that could be deployed as needed. Having a plan in place for remote continuity of learning at the school level and school-district level was recommended as well familiarizing all stakeholders with the plan to respond to future crises, similar to recommendations in the crisis management literature (Baytiyeh, 2019; Barker \& Yoder, 2012; Gainey, 2009; Holzweiss \& Walker, 2018; Smith \& Riley, 2012; Zdziarski, 2016). Participants also advocated for university coursework to include remote continuity of learning plan development that included best practices and ways to support teachers 
and school leaders at varying levels of experience. Additionally, participants recommended that the lived pandemic experiences of educational leaders be incorporated in educational leadership coursework.

Findings from this study suggest that although teachers and educational leaders perceived some level of preparation for remote continuity of learning when stay-at-home orders were issued, more needs to be done by school districts and educational leadership preparation programs to prepare for future crises that may require suspension of in-person classes. Similar to the findings of Zhang et al. (2020), participants in this study indicated technology infrastructure to support all learners, particularly under-resourced learners, and teaching modes and online teaching pedagogy as critical aspects of future preparation for remote continuity of learning. Participants also highlighted the high value of interactions with colleagues in preparing them for remote continuity of learning, pointing to the role educational leaders could take in future crises to facilitate and ensure collaboration for problem-solving, instructional expertise, and reflection among staff (Brelsford et al., 2020; Hauseman et al., 2020). School district professional learning and educational leadership programs can assist by incorporating coursework that explicitly addresses digital tools, pedagogical practices related to digital tools, and digital instructional leadership practices (Koehler \& Mishra, 2009; Shepherd \& Taylor, 2019).

\section{Conclusion}

The attending results of the COVID-19 pandemic crisis on educational systems threw into sharp relief the aspects of remote continuity of learning that need to be addressed to ensure teachers' and educational leaders' preparation for future crises. Although this study was comprised of a small sample of participants within a one geographic area, the findings aligned with studies completed during the first wave of the pandemic. While we know that the findings from this study are not generalizable given its scope, the findings may contribute to future studies, focusing on the components that teachers and educational leaders perceive to be the most timely and important to prepare for future instances of remote continuity of learning. It is evident that as an educational sector, we were unevenly prepared to respond to this crisis to meet the needs of school communities. However, analysis of the preparedness during the COVID-19 crisis will assist in the creation of robust supports to prepare educators.

\section{References}

Anderson, A. (2020). COVID-19 outbreak highlights critical gaps in school emergency preparedness. https://www.brookings.edu/blog/education-plus-development/2020/03/11/COVID-19-outbreakhighlights-critical-gaps-in-school-emergency-preparedness/

Barker, G. G., \& Yoder, M. E. (2012). The Virginia Tech shootings: Implications for crisis communication in educational settings. Journal of School Public Relations, 33(2), 78-101. https:/ / doi.org/10.3138/jspr.33.2.78

Baytiyeh, H. (2019). Why school resilience should be critical for the post-earthquake recovery of communities in divided societies. Education and Urban Society, 51(5), 693-711.

Brelsford, S. N., Camarillo, E. E., Garcia, A. S., Garcia, G., Lopez, V. R., Montoya, C. P., Mora R., III, Olvera, Z., Ramirez, A., Wicker, F., \& Merchant, B. (2020). Keeping the bus moving while maintaining social distance in a COVID-19 world. International Studies in Educational Administration, 48(2), 12-20.

British Medical Journal. (1883). The closing of schools as a sanitary measure. British Medical Journal, 2(1181), 341-342.

Center for Disease Control [CDC]. (2020). Considerations for institutions of higher education. https://www.cdc.gov/coronavirus/2019-ncov/community/collegesuniversities/considerations.html\#principles

Creswell, J. W.,\& Creswell, J. D. (2018). Research design: Qualitative, quantitative, and mixed methods approaches (5 $5^{\text {th }}$ ed.). Sage.

Deloitte. (n. d.) Combating COVID-19: Explore a sector specific insights and actions. https://www2.deloitte.com/global/en/pages/about-deloitte/articles/COVID-19-insights-collection-bysectors.html 
Dillman, D. A., Smyth, J. D., \& Christian, L. M. (2009). Internet, mail, and mixed-mode surveys: The tailored design method (3rd ed.). John Wiley \& Sons, Inc.

Florida Department of Education. (n.d.) Coronavirus (COVID-19). https://www.fldoe.org/emresponse/index.stml

Gainey, B. S. (2009). Crisis management's new role in educational settings. The Clearing House: A Journal of Educational Strategies, Issues and Ideas, 82(6), 267-274. https:// doi.org/10.3200/TCHS.82.6.267-274

Glaser, B. G. \& Strauss, A. L. (2008). The Discovery of Grounded Theory: Strategies for Qualitative Research. AldineTransaction.

Harris, A. \& Jones, M. (2020). COVID-19: School leadership in disruptive times. School Leadership \& Management, 40(4), 243-247. https:// doi.org/1080/13632434.2020.1811479

Hattie, J. (2009). Visible Learning: A Synthesis of Over 800 Meta-Analyses Relating to Achievement. Routledge.

Hauseman, C., Darazsi, S., \& Kent, S. (2020). Collaboration, communication and wellness: Response to the COVID-19 pandemic in Manitoba schools. International Studies in Educational Administration, 48(2), 70-77.

Holzweiss, P. \& Walker, D. (2018). Higher education crises: Training new professionals for crisis management. The College Student Affairs Journal, 36(1), 124-135.

Koehler, M. J. \& Mishra, P. (2009). What is technological pedagogical content knowledge? Contemporary Issues in Education, 9(1), 60-70.

Miami-Dade County Public Schools. (n. d.). Instructional continuity plan 2.0. Dade Schools. https://icp.dadeschools.net/\#!/fullWidth/2943

Michigan Department of Education. (n .d.) MDE COVID-19 education information and resources. https:/ / michigan.gov/mde/0,4615,7-140-37818_53456---,00.html

Mueller, R. O. \& Knapp, T. R. (2019). Reliability and Validity. In G. R. Hancock, L. M. Stapleton, \& R. O. Mueller (Eds.), The Reviewer's Guide to Quantitative Methods in the Social Sciences (pp. 397-401). Routledge.

Netolicky, D. M. (2020). School leadership during a pandemic: Navigating tensions. Journal of Professional Capital and Community, 5(3/4), 391-395. https:/ / doi.org/10.1108/JPCC-05-2020-0017

New Jersey Department of Education. (n.d.) Guiding the education community through the COVID-19 pandemic. https://www.nj.gov/education/covid19/

Saldaña, J. (2016). The coding manual for qualitative researchers. SAGE Publications Ltd.

Shepherd, A. C. \& Taylor, R. T. (2019). An analysis of factors which influence high school administrators' readiness and confidence to provide digital instructional leadership. The International Journal of Educational Leadership Preparation, 14(1), 52-76.

Smith, L., \& Riley, D. (2012). School leadership in times of crisis. School Leadership \& Management, 32(1), 5771. https:/ / doi.org10.1080/13632434.2011.614941

Tucker, J. A. (2020). No lockdowns: The terrifying polio pandemic of 1949-1952. AIER. https://www.aier.org/article/no-lockdowns-the-terrifying-polio-pandemic-of-1949-52/

U.S. Department of Education. (2009). Preparing for the flu: Department of Education recommendations to ensure the continuity of learning for schools $(\mathrm{K}-12)$ during extended student absence or school dismissal (ED506275). ERIC. https:/ / files.eric.ed.gov/fulltext/ED506275.pdf

United Nations Educational, Scientific and Cultural Organization [UNESCO]. (n.d.) COVID-19 education response. https://en.unesco.org/covid19/educationresponse/globalcoalition

Zdziarski, E, II. (2016). Campus crisis: It's not just about responding. Presidency (Washington, D.C.), 29(2), 2630.

Zhang, W., Wang, Y., Yang, L., \& Wang, C. (2020). Suspending classes without stopping learning: China's education emergency management policy in the COVID-19 outbreak. Journal of Risk and Financial Management, 13(3), 1-6. https:/ / doi.org/10.3390/jrfm13030055 